\title{
The Development of A Survey Instrument: Assessing University Students' Perception On The Quality of Classroom Assessment
}

\author{
Faridah \\ Department of Educational Administration \\ Universitas Negeri Makassar \\ Indonesia \\ faridah@unm.ac.id
}

\author{
Arismunandar \\ Department of Educational Administration \\ Universitas Negeri Makassar \\ Indonesia \\ arismunandar@unm.ac.id
}

\begin{abstract}
This paper focuses on the development of a survey instrument on students' perception of the quality of classroom assessment in university. The theoretical framework use in the development of the questionnaire is the principles of sound assessment of students' learning. This paper begins with an overview of classroom assessment and the principals of educational assessment. The instrument design and development is presented to show how items are constructed including the format of the response choice. Literatures on survey and questionnaire are used to justify the selection.
\end{abstract}

Keywords-educational assessment; higher education; university; survey; Indonesia

\section{INTRODUCTION}

The increasing demand of accountability has led any educational institution to carefully develop and use its assessment. According to Miller et al., educational improvement must begin with a clear idea of what students are expected to learn [1]. In a broad term, Nitko \& Brookhart define assessment as "a process for obtaining information that is used for making decisions about students, curricula, programs, schools, and educational policy" (p.3) [2].

The aim of assessment is to provide information for teacher to make decision about teaching, and for students to make decision about learning [2]. Earl argues that the predominant purpose of assessment in school was summative, which intended to certify learning in the form of grade [3]. She believes assessment should encourage students to engage on learning and empower them to ask reflective questions to improve their learning. Hence, students are the central focus of any classroom assessment.

In higher education, the use of assessment has strongly focused on students outcomes [4]-[6]. Reviewing studies on assessment in the American Journal of Pharmaceutical Education, Anderson et al. report that in the field of Pharmaceutical Education, assessment has mainly been conducted to assess student, program, and curriculum (teaching and learning) [4]. The emphasis is on student's progress, motivation, and outcomes. The various ways of using and assessment are also shown by Pascarella \&
Terenzini [6]. Their study was on the various elements of college education that affect students' outcomes in a period of 1989 - 1990. The students' outcomes are classified as cognitive development, values, attitudes, career, subject matter competence, and quality of life.

Those studies show that research on assessment is mainly about assessing students' outcomes. Rather than assessing students' outcomes, this paper, focuses on what students think about the quality of classroom assessment they have experienced. This is in line with Donald \& Denison argue that students and their perceptions need to incorporated in to the assessment process [5]. They believe that it is critical to identify the potential areas of different interpretations that might influence the validity of an assessment.

\section{Key PRINCIPALS OF EdUCATIONAL ASSESSMENT}

Airasian writes that classroom assessment is "the process of collecting, synthesizing, and interpreting information to aid in classroom decision making" (p.2). It is an ongoing part of teaching, and is not separated from the classroom activity [7]. Nitko \& Brookhart state that a good assessment means a good instruction [2]. A good assessment should allow teacher to provide meaningful feedback to students. Similarly, Stiggins argues that assessment relates to the quality of instruction [8] Further, Earl believes that assessment should allow students to do self-monitoring that lead them to decide what to do next after realizing that they do not understand something [3]. She suggests that effective assessment should empower students to ask reflective questions and consider a range of strategies for learning.

According to Stiggins, high-quality assessment must have clear objectives, focused purpose, proper method, and accurate assessment that is free of bias and distortion [8]. Nitko \& Brookhart suggest that the key principle of educational assessment is the interrelationships between the learning objectives, the assessment task, the assessment techniques, and the achievement indicators [2].

Based on the critical ideas of assessment that are addressed in the literature, four elements of assessment are used in developing the questionnaire in this study, they are: the 
learning objectives (LO), classroom activities (CA), the assessment task (AT), and the assessment criteria (AC).

\section{INSTRUMENT DESIGN AND DEVELOPMENT}

\section{A. Structure of the Questionnaire}

The structure of the instrument is divided into four scales: (1) learning objectives (LO), (2) classroom activities (CA), (3) assessment task (AT), and (4) assessment criteria (AC). The subscales are orderly presented from learning objectives to assessment criteria. The reason behind the structure is because the sequences of classroom assessment begin with (1) clear statement of learning objectives, (2) how the classroom activities are managed to meet the learning objectives, (3) what assessment task should be performed by students to obtain the information of their learning, and (4) what criteria are used to assess students' work.

Overall there are 25 items in the questionnaire, 5 items are for the learning objectives, 8 items for the classroom activities, 6 items for the assessment task, and 6 items for the assessment criteria. For each scale, one open ended question is given asking about what aspects need to be improved for each scale based on their experience during their study. Moreover, demographic questions are also given and placed at the end of the questionnaire. Questions related to demographic questions are gender, year enrolled, study program, and student ID (for administrative purpose only). One open ended question are also provided to obtain feedback on the questionnaire.

\section{B. Construct Representation}

According to Rattray \& Jones, it is critical to understand what a questionnaire wants to assess [9]. This will guide the development of items that represent the main construct. In this study, the development of the items is basically followed what literature on assessment said. Airasian writes that learning objectives must have clear answer, must represent important aspect of lesson learned, and must be achievable in a reasonable of time [7]. A good assessment must begin with clear purposes [8]. In addition, Wiggins states that the tasks and criteria of assessment should be known by both, teacher and students [10]. Nitko \& Brookhart argue that assessment should allow teacher to provide meaningful feedback to students [2]. Further, Stiggins highlights that the value of achievement target should be communicated effectively to students [8].

Based on those literatures, the key of the quality of the classroom assessment is represented in items for each scale. For instance, there are items ask about the clarity of learning objectives, the specificity of learning objectives, the availability of feedback, and the clarity of assessment criteria.

\section{Response Options and Labelling}

Likert type question is used in the questionnaire with five response options. Rattray \& Jones state that a Likert-type scale assumes the linear experience of agreement /disagreement, which makes the assumption, that attitudes can be measured [9]. The middle point option is provided in the options. Studies on middle point options report that the availability of middle point could lead respondent to select it [11], but the absence of it could possibly lower the validity of the questionnaire. In this questionnaire, it is the nature of the question that leads to the decision to also include the middle point option. There is a possibility that respondent does not agree nor disagree to the items asked.

Verbal labels are also used in the questionnaire, from strongly disagree to strongly agree, with the middle option, neither agree nor disagree. The verbal labels are placed in all responses options. The direction of the response options begins from less socially desirable response, strongly disagree, to prevent respondents from making a choice without having read other available options [11].

\section{Question Order}

According to Lietz question order will give impact when one question is more general regarding a certain concept while the other is more specific [11]. She reports that general question is more appropriately placed before the specific question. Rattray \& Jones also believe that the type of question and the order of items could lead to bias response [9].

Items in this questionnaire begin from general question, and are designed to follow the actual learning process in the classroom. It begins with the availability of assessment criteria, whether they are clear, whether students are well informed on the indicators, following by the availability of feedback from teacher. For examples: for Learning Objective scale, the questionnaire begins with asking whether the learning objectives are clear that students know what to achieve. For the scale of Assessment Criteria (AC), the item begins with asking whether criteria to assess students' work are provided. This principle applies to all items order on each scale.

\section{E. Choice of Wording}

Items in the questionnaire are all positively worded. Although Rattray \& Jones argue that the used of both positively and negatively worded items might minimize the tendency to respond in the same way to all items, others believe that negatively worded question should not be included in items, because it leads respondents to make mistake and increase the cognitive load on respondent to think of the actual meaning of the item [11]. Considering that the intended respondents are students, the positively worded items are selected which do not require additional thinking process, particularly when the words used are also simple and easy to understand.

\section{F. Social Desirability}

The intended participants are university students. To encourage students to provide honest responses, a third person (students) is used instead of "I". In addition, although the purpose of the questionnaire is to investigate students' perceptions of the quality of classroom assessment, the questions can be perceived as assessing their teacher and/or their learning in relation to assessment. By projecting their own view on to others, it is expected that they would answer the questions easily [11]. For example, Q.4 on Assessment 
Task: "Students are well informed of how the assessment task will be assessed".

\section{G. Open-ended Questions}

Rattray \& Jones argue that open-ended questions will allow participants to expand their answers [9]. The openended questions are provided in the questionnaire to allow students to give comments or address issues regarding the four elements of the assessment, which might not be addressed in the items. However, there are some issues on open-ended question.

According to Salant \& Dillman, open-ended questions can be very demanding for respondents, may yield no more than a few mentions of any one topic, and can be difficult to code [12]. Despite the limitations, they suggest that open-ended questions can be used to obtain information that has been overlooked by the researcher. Five open-ended questions are provided in the questionnaire, four questions are related to the quality of the classroom assessment, and one question is regarding the questionnaire itself. The questions are designed to be as specific as possible, to guide students to give clear and specific answers. One example of the questions is: What aspects do you think need to improve regarding assessment task and/or assessment criteria?

\section{INSTRUMENT EVALUATION}

To ensure the validity of the questionnaire, the developed instrument was evaluated through expert review and cognitive interviews. The expert review was done by consulting whether the scale and the items represent the interrelationship of the elements of classroom assessment. Inputs were given regarding the calculation of reliability and several items that can also be analyzed by creating new subscales. Two cognitive interviews were conducted to receive feedback on the readability of each item. Cognitive interviews have provided valuable feedback regarding the clarity of particular words that might not be understandable by students. Many items were revised based on the feedback provided.

In the original draft of the questionnaire, there were no descriptions of what the scales mean. On the cognitive interviews, it was suggested to provide a description of each scale to make sure the participants understand what the questions are about. Some words were also changed to prevent participants to question the meaning. There are questions were deleted due to the repetition. For demographic questions, initially there was no identification asked. However, for administrative purpose, it was suggested to ask for name. Instead of asking name, student ID is asked with a notification, that it is intended for administrative purpose only. Basically, some changes are made to help participants understand the items and to prevent them from experiencing cognitive overload.

\section{CONCLUSION}

The use of literature on survey and questionnaire is critical in developing a survey instrument. Combining with the purpose of the assessment in this study, the development of the questionnaire has tried to consider various factor in developing the scales and items. This questionnaire is developed to asses students perceptions on the quality of classroom assessment they have experienced. It should be further tested to measure the reliability and validity. It is also important to give attention on the readability of the questionnaire, considering the characteristics of the intended participants of the study.

\section{Acknowledgment}

We would like to thank Universitas Negeri Makassar for providing research grant to conduct this study. Hopefully, this study will be beneficial for the improvement of the quality of classroom assessment UNM.

\section{References}

[1] M. D. Miller, R. L. Linn, and N. E. Gronlund, Measurement and assessment in teaching. Pearson Higher Ed, 2012.

[2] A. J. Nitko and S. M. Brookhart, Educational assessment of students (6th ed.). Boston: Pearson Education, Inc., 2011.

[3] L. M. Earl, Assessment as learning: Using classroom assessment to maximize student learning. Corwin Press, 2012.

[4] H. M. Anderson, G. Anaya, E. Bird, and D. L. Moore, 'A review of educational assessment', Am. J. Pharm. Educ., vol. 69, no. 1, p. 12, 2005.

[5] J. G. Donald and D. B. Denison, 'Quality assessment of university students: Student perceptions of quality criteria', J. Higher Educ., vol. 72, no. 4, pp. 478-502, 2001.

[6] E. T. Pascarella and P. T. Terenzini, 'How college affects students: A third decade of research (Vol. 2)'. San Francisco: Jossey-Bass, 2005.

[7] P. W. Airasian, Classroom Assessment-Concepts and Applications, 5th. McGraw-Hill, Boston, MA, 2005.

[8] R. J. Stiggins, Student-centered Classroom Assessment. Merrill, 1997.

[9] J. Rattray and M. C. Jones, 'Essential elements of questionnaire design and development', J. Clin. Nurs., vol. 16, no. 2, pp. 234-243, 2007.

[10] G. Wiggins, Educative Assessment. Designing Assessments To Inform and Improve Student Performance. ERIC, 1998.

[11] P. Lietz, Questionnaire design in attitude and opinion research: Current state of an art. Citeseer, 2008.

[12] P. Salant and D. A. Dillman, 'How to Conduct your own Survey: Leading professional give you proven techniques for getting reliable results'. New York, NY: John Wiley \& Sons, Inc, 1994.

[1] M. D. Miller, R. L. Linn, and N. E. Gronlund, Measurement and assessment in teaching. Pearson Higher Ed, 2012.

[2] A. J. Nitko and S. M. Brookhart, Educational assessment of students (6th ed.). Boston: Pearson Education, Inc., 2011.

[3] L. M. Earl, Assessment as learning: Using classroom assessment to maximize student learning. Corwin Press, 2012.

[4] H. M. Anderson, G. Anaya, E. Bird, and D. L. Moore, 'A review of educational assessment', Am. J. Pharm. Educ., vol. 69, no. 1, p. 12, 2005.

[5] J. G. Donald and D. B. Denison, 'Quality assessment of university students: Student perceptions of quality criteria', J. Higher Educ., vol. 72, no. 4, pp. 478-502, 2001.

[6] E. T. Pascarella and P. T. Terenzini, 'How college affects students: A third decade of research (Vol. 2)'. San Francisco: Jossey-Bass, 2005.

[7] P. W. Airasian, Classroom Assessment- Concepts and Applications, 5th. McGraw-Hill, Boston, MA, 2005.

[8] R. J. Stiggins, Student-centered Classroom Assessment. Merrill, 1997. 
[9] J. Rattray and M. C. Jones, 'Essential elements of questionnaire design and development', J. Clin. Nurs., vol. 16, no. 2, pp. 234-243, 2007.

[10] G. Wiggins, Educative Assessment. Designing Assessments To Inform and Improve Student Performance. ERIC, 1998.

[11] P. Lietz, Questionnaire design in attitude and opinion research: Current state of an art. Citeseer, 2008.

[12] P. Salant and D. A. Dillman, 'How to Conduct your own Survey: Leading professional give you proven techniques for getting reliable results'. New York, NY: John Wiley \& Sons, Inc, 1994. 